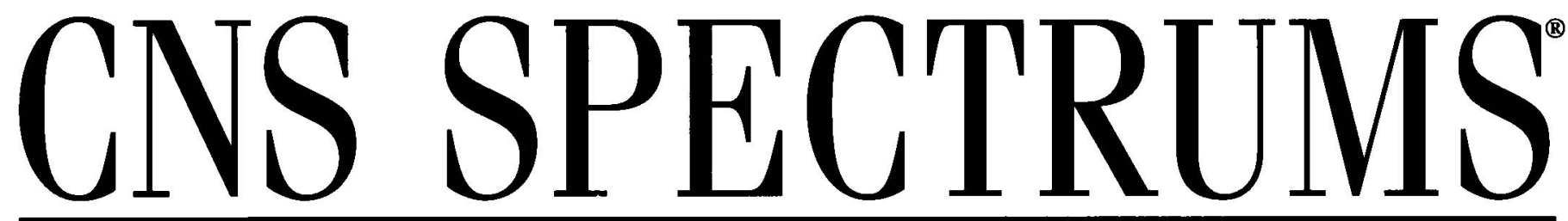

The International Journal of Neuropsychiatric Medicine

\title{
ACADEMIC SUPPLEMENT \\ Anxiety and Depression in the Elderly: \\ Implications for Diagnosis and Treatment
}

Introduction

D.L. Dunner

Treatment Considerations for Anxiety in the Elderly

E.J. Lenze, B.G. Pollock, M.K. Shear, B.H. Mulsant,

A. Bharucha, and C.F. Reynolds III

Treatment Considerations for Depression in the Elderly

D.L. Dunner

Medically Unexplained Physical Symptoms:

Toward an Alternative Paradigm for Diagnosis and Treatment

C.A. Ballas and J.P. Staab

Achieving Long-Term Optimal Outcomes

in Geriatric Depression and Anxiety

B.H. Mulsant, E. Whyte, E.J. Lenze, F. Lotrich,

J.F. Karp, B.G. Pollock, and C.F. Reynolds III

Quality of Life in Geriatric Patients with Mood and Anxiety Disorders

R.E. Maddux, K.K. Delrahim, and M.H. Rapaport

Adherence to Treatment for Geriatric Depression and Anxiety

J.L. Wetherell and J. Unützer 
Faculty Affiliations and Disclosure

Dr. Ballas is instructor in the Department of Psychiatry at the Hospital of the University of Pennsylvania in Philadelphia. He is on the Speaker's Bureau of AstraZeneca, Eli Lilly, Pfizer, and Wyeth.

Dr. Bharucha is assistant professor of psychiatry in the Department of Psychiatry at the University of Pittsburgh School of Medicine in Pennsylvania. He is on the Speaker's Bureau of Forest.

Ms. Delrahim is a research associate in the Department of Psychiatry at Cedars Sinai Medical Center in Los Angeles, California. She reports no affiliation with or financial interest in a commercial organization that might pose a conflict of interest.

Dr. Dunner is director of the Center for Anxiety and Depression and professor in the Department of Psychiatry and Behavioral Sciences at the University of Washington in Seattle. Dr. Dunner is a consultant to Bristol-Myers Squibb, Corcept, Cypress, Eli Lilly, GlaxoSmithKline, Novartis, Otsuka, Pfizer, and Wyeth; is on the Speaker's Bureau of Bristol-Myers Squibb, Eli Lilly, Forest, GlaxoSmithKline, Organon, Pfizer, and Wyeth; and receives research support from Cyberonics, Eli Lilly, GlaxoSmithKline, Janssen, Merck, Pfizer, and Wyeth.

Dr. Karp is a research fellow in the Department of Psychiatry at the University of Pittsburgh School of Medicine in Pennsylvania. He reports no affiliation with or financial interest in a commercial organization that might pose a conflict of interest.

Dr. Lenze is assistant professor of psychiatry in the Department of Psychiatry at the University of Pittsburgh School of Medicine in Pennsylvania. He has received grant support from Forest, Janssen, and Pfizer.

Dr. Lotrich is a research fellow in the Department of Psychiatry at the University of Pittsburgh School of Medicine in Pennsylvania. He reports no affiliation with or financial interest in a commercial organization that might pose a conflict of interest.

Ms. Maddux is a research associate in the Department of Psychiatry at Cedars Sinai Medical Center in Los Angeles, California. She reports no affiliation with or financial interest in a commercial organization that might pose a conflict of interest.

Dr. Mulsant is associate professor of psychiatry in the Department of Psychiatry at the University of Pittsburgh School of Medicine in Pennsylvania. He is a consultant to AstraZeneca, Bristol-Myers Squibb, Eli Lilly, Forest, GlaxoSmithKline, Janssen, and Pfizer; is on the Speaker's Bureau of AstraZeneca, Forest, GlaxoSmithKline, Janssen, and Pfizer; and has received honoraria or grant support from AstraZeneca, Corcept, Eisai, Eli Lilly, Forest, GlaxoSmithKline, Janssen, Lundbeck, and Pfizer.

Dr. Pollock is professor of psychiatry and pharmacology in the Department of Psychiatry at the University of Pittsburgh School of Medicine in Pennsylvania. He is a consultant to AstraZeneca, Forest, GlaxoSmithKline, Janssen, NPS Pharmaceuticals, and Organon; is on the Speaker's Bureau of Forest, and has received grant/research support from Forest, GlaxoSmithKline, and Janssen.

Dr. Rapaport is chair of the Department of Psychiatry at Cedars Sinai Medical Center and vice chair of the Department of Psychiatry at the University of Los Angeles, California. He has received research support or honoraria from Abbott, Bristol-Myers Squibb, Eli Lilly, Forest, GlaxoSmithKline, Novartis, Pfizer, Pharmacia and Upjohn, Robert Wood Johnson, Sanofi-Synthelabo, and Wyeth; has served as a consultant to Eli Lilly, Forest, Janssen, Pfizer, Pharmacia \& Upjohn, and Sanofi-Synthelabo; and has been on the Speaker's Bureau of Eli Lilly, Forest, Janssen, Pfizer, Pharmacia \& Upjohn, and GlaxoSmithKline.

Dr. Reynolds is professor of psychiatry, neurology, and neuroscience, and director of the Intervention Research Center in Late-Life Mood Disorders, in the Department of Psychiatry at the University of Pittsburgh School of Medicine in Pennsylvania. He is on the Speaker's Bureau of and has received research support from Forest and GlaxoSmithKline.

Dr. Shear is professor of psychiatry in the Department of Psychiatry at the University of Pittsburgh School of Medicine in Pennsylvania. She is a consultant to and on the Speaker's Bureau of GlaxoSmithKline and Pfizer; and has received research grants from Forest and Pfizer.

Dr. Staab is assistant professor of psychiatry in the Departments of Psychiatry and Otorhinolaryngology - Head and Neck Surgery, and director of Psychiatric Services at the Hospital of the University of Pennsylvania in Philadelphia. He is a consultant to Janssen and Pfizer; on the Speaker's Bureau of Forest, Janssen, and Pfizer; and has received research grants from Pfizer.

Dr. Unützer is professor and vice chair of psychiatry at the University of Washington School of Medicine in Seattle. He reports no affiliation with or financial interest in a commercial organization that might pose a conflict of interest.

Dr. Wetherell is assistant professor in residence in the Department of Psychiatry at the University of California, San Diego, and staff psychologist in the Veteran's Affairs San Diego Healthcare System. She reports no affiliation with or financial interest in a commercial organization that might pose a conflict of interest.

Dr. Whyte is assistant professor of psychiatry in the Department of Psychiatry at the University of Pittsburgh School of Medicine in Pennsylvania. She has received grant support from Janssen and Pfizer.

Disclaimer

This academic supplement is supported via an unrestricted educational grant from GlaxoSmithKline. Sponsorship of this review does not imply the sponsor's agreement with the views expressed herein.

Although every effort has been made to ensure that drug doses and other information are presented accurately in this publication, the ultimate responsibility rests with the prescribing physician. Neither the publisher, the sponsor, nor the authors can be held responsible for errors or for any consequences arising from the use of information contained herein. Readers are strongly urged to consult any relevant primary literature. No claims or endorsements are made for any drug or compound currently under clinical investigation.

Copyright (C2003, MBL Communications, Inc.

333 Hudson St., 7th Floor, New York, NY 10013.

Printed in the USA. All rights reserved, including the right of reproduction, in whole or in part, in any form. 


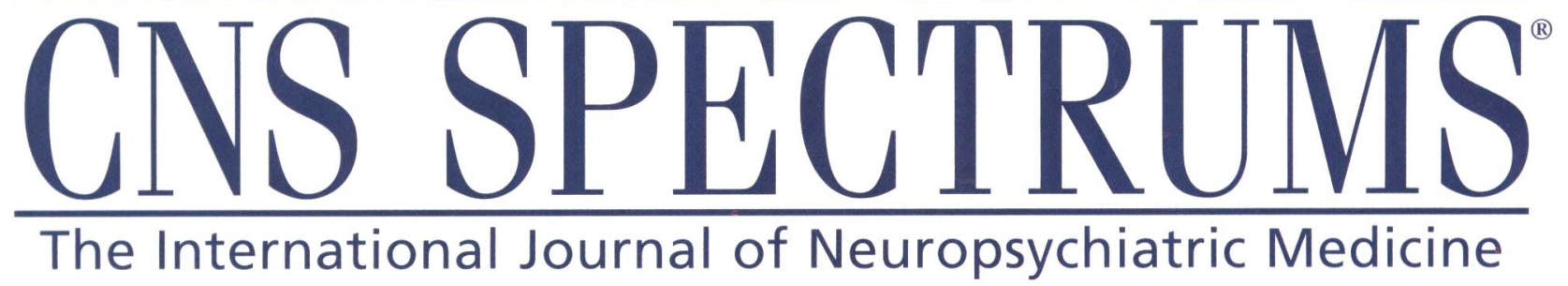

\section{EDITOR}

Jack M. Gorman, MD

Mount Sinai School of Medicine New York, NY

ASSOCIATE AND FOUNDING EDITOR

Eric Hollander, MD

Mount Sinai School of Medicine

New York, NY

\section{INTERNATIONAL EDITOR}

Joseph Zohar, MD

Chaim Sheba Medical Center

Tel-Hashomer, Israel

\section{ASSOCIATE INTERNATIONAL EDITORS EUROPE}

Donatella Marazziti, MD

University of Pisa

Pisa, Italy

\section{MID-ATLANTIC}

Dan J. Stein, MD, PhD

University of Stellenbosch

Tygerberg, South Africa

\section{FAR EAST}

Shigeto Yamawaki, MD, PhD

Hiroshima University School

of Medicine

Hiroshima, Japan

\section{MEDICAL REVIEWER}

David L. Ginsberg, MD

New York University Medical Center

New York, NY

\section{BOARD OF ADVISORS \\ NEUROLOGISTS}

Mitchell F. Brin, MD

University of California, Irvine

Irvine, CA

Jeffrey L. Cummings, MD

University of California, Los Angeles

Los Angeles, CA
Jerome Engel, Jr., MD, PhD

University of California, Los Angeles Los Angeles, CA

Mark S. George, MD

Medical University of South Carolina

Charleston, SC

Richard B. Lipton, MD

Albert Einstein College of Medicine

Bronx, NY

C. Warren Olanow, MD, FRCPC

Mount Sinai School of Medicine New York, NY

Steven George Pavlakis, MD

Maimonides Medical Center

Brooklyn, NY

Stephen D. Silberstein, MD, FACP

Thomas Jefferson University

Philadelphia, PA

Michael Trimble, MD, FRCP, FRPsych National Hospital for Neurology and Neurosurgery

London, United Kingdom

\section{PSYCHIATRISTS}

Margaret Altemus, MD

Cornell University Medical College

New York, NY

Dennis S. Charney, MD

National Institute of Mental Health

Bethesda, MD

Dwight L. Evans, MD

University of Pennsylvania

Philadelphia, PA

Siegfried Kasper, MD

University of Vienna

Vienna, Austria

Martin B. Keller, MD

Brown Medical School

Providence, RI

Lorrin M. Koran, MD

Stanford University School of Medicine

Stanford, CA

Yves Lecrubier, MD

Hôpital de la Salpêtrière

Paris, France

Herbert Y. Meltzer, MD

Vanderbilt University Medical Center Nashville, TN

Stuart A. Montgomery, MD

St. Mary's Hospital Medical School

London, United Kingdom

Charles B. Nemeroff, MD, PhD

Emory University School of Medicine

Atlanta, GA

Humberto Nicolini, MD, PhD

National Mexican Institute of Psychiatry

Mexico City, Mexico

Stefano Pallanti, MD, PhD

University of Florence

Florence, Italy

Katharine Phillips, MD

Brown Medical School

Providence, RI

Harold A. Pincus, MD

Western Psychiatric Institute \& Clinic RAND-University of Pittsburgh Health Institute, Pittsburgh, PA

Scott L. Rauch, MD

Massachusetts General Hospital Charlestown, MA

Alan F. Schatzberg, MD

Stanford University School of Medicine

Stanford, CA

Thomas E. Schlaepfer, MD

University of Bonn

Bonn, Germany

Stephen M. Stahl, MD, PhD

University of California, San Diego

La Jolla, California

Norman Sussman, MD, DFAPA

New York University Medical School New York, NY

Karen Dineen Wagner, MD, PhD

The University of Texas Medical Branch

Galveston, TX

Herman G.M. Westenberg, MD

University Hospital Utrecht

Utrecht, The Netherlands

Stuart C. Yudofsky, MD

Baylor College of Medicine Houston, TX

MBL COMMUNICATIONS Corporate Staff

CEO \& PUBLISHER

Darren L. Brodeur

ASSOCIATE PUBLISHER

Elizabeth Katz

MANAGING EDITOR

Christopher Naccari

SENIOR EDITOR

Deborah Hughes

DEPUTY SENIOR EDITOR

José R. Ralat

ACQUISITIONS EDITOR

Lisa Arrington

ASSISTANT ACQUISITIONS EDITOR
Eileen S. Seligman
ASSISTANT EDITOR
Emil J. Ross
EDITORIAL ASSISTANT
Shelley Wong
PRODUCTION MANAGER
Lila Moses
GRAPHIC DESIGNER
Anthony J. Korsak
CONTROLLER
John Spano

NATIONAL ACCOUNT MANAGER

Kelly J. Staley

INFORMATION TECHNOLOGY

Greg Taube

OFFICE MANAGER

Claudette Crawford

OFFICE ASSISTANT

Manuel Pavón

CORPORATION COUNSEL

Lawrence Ross, Esq.

Bressler, Amery, and Ross

\section{EDITORIAL MISSION}

CNS Spectrums' editorial mission is to address relevant neuropsychiatric topics, including the prevalence of comorbid diseases among patients, and original research and reports that emphasize the profound diagnostic and physiologic connections made within the neurologic and psychiatric fields. The journal's goal is to serve as a resource to psychiatrists and neurologists seeking to understand and treat disturbances of cognition, emotion, and behavior as a direct consequence of central nervous system disease, illness, or trauma. 


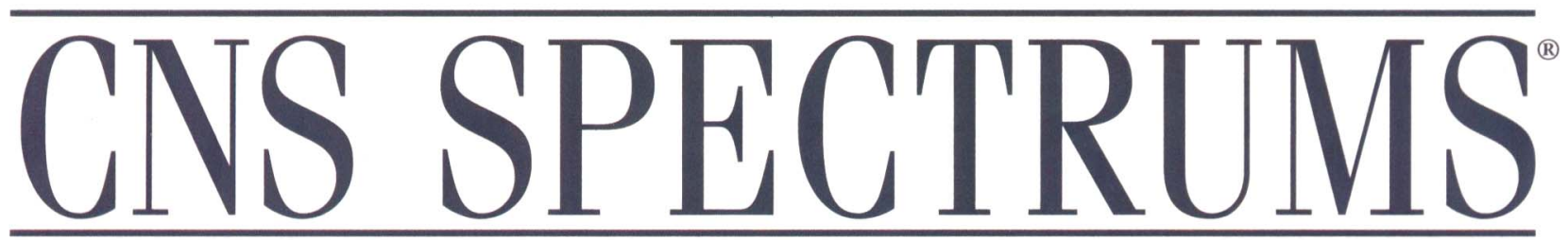

The International Journal of Neuropsychiatric Medicine

\section{Table of Contents}

\section{December 2003}

Volume 8 - Number 12 - Supplement 3

\section{Introduction}

By David L. Dunner, MD, FACP

6 Treatment Considerations for Anxiety in the Elderly By Eric J. Lenze, MD, Bruce G. Pollock, MD, PhD, $M$. Katherine Shear, MD, Benoit H. Mulsant, MD, Ashok Bharucha, MD, and Charles F. Reynolds III, MD

14 Treatment Considerations for Depression in the Elderly By David L. Dunner, MD, FACP

20 Medically Unexplained Physical Symptoms: Toward an Alternative Paradigm for Diagnosis and Treatment By Christos A. Ballas, MD, and Jeffrey P. Staab, MD

\section{Achieving Long-Term Optimal Outcomes} in Geriatric Depression and Anxiety By Benoit H. Mulsant, MD, Ellen Whyte, MD, Eric J. Lenze, MD, Francis Lotrich, MD, PhD, Jordan F. Karp, MD, Bruce G. Pollock, MD, PhD, and Charles F. Reynolds III, MD

35 Quality of Life in Geriatric Patients with Mood and Anxiety Disorders

By Rachel E. Maddux, BA, Katia K. Delrahim, BA, and Mark H. Rapaport, MD

48 Adherence to Treatment for Geriatric Depression and Anxiety

By Julie Loebach Wetherell, PhD, and Jürgen Unützer, MD, MPH

CNS Spectrums is an Index Medicus journal and is available on MEDLINE under the citation CNS Spectr.

It is also indexed by DIALOG, EMBASE/Excerpta Medica, ÓVID, Lexis-Nexis, and SilverPlatter.

\section{CNS Spectrums ${ }^{\circledR}$}

(ISSN 1092-8529)

is published monthly by

MBL Communications, Inc.

333 Hudson Street, 7 th Floor

New York, NY 10013

One year subscription rates:

domestic $\$ 120$

foreign $\$ 185$

in-training $\$ 75$.

For subscriptions, Fax: 212-328-0600

Web site: www.cnsspectrums.com

For editorial inquiries:

dh@mblcommunications.com

Postmaster:

Send address changes to

CNS Spectrums

clo PPS Medical Marketing Group

264 Passaic Avenue

Fairfield, NJ 07004-2595

Opinions and views expressed by authors are their own and do not necessarily reflect the views of the publisher, MBL Communications, Inc., or the editorial advisory board.

CNS Spectrums $\circledast$ is a registered trademark of CNS Spectrums, LLC, New York, NY.

Permission to reproduce articles in whole or in part must be obtained in writing from the publisher.

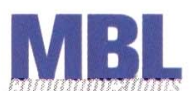

Copyright $\mathrm{C} 2003$ by MBL

Communications, Inc. All rights reserved.

Printed in the United States. 